\title{
As many rules as necessary, as few as possible. The traps of deregulated sex positive spaces with a focus on gender inequality
}

\author{
Anna Mense ${ }^{1}$ \\ Justus Liebig University (Germany) \\ Anna.mense@uni-rostock.de
}

\section{Abstract}

In order to explain suffering in contemporary romantic relationships, Eva Illouz (2012) looks at the consequences of the detachment of erotic and romantic encounters from committed relationships such as marriage. While this detachment is often referred to as a triumph of free choice and liberal loving, Illouz argues that it causes systemic inequalities between male and female agents. The article takes Illouz's analysis as an incentive and a basis to study deregulated sex-positive spaces with regards to their risk to involuntarily reproduce features of socio-political domination. The discussion is driven by an interest in the question how options to explore sexual and romantic relationships can be developed without reproducing systemic disadvantages of heteronormative culture.

In Why Love Hurts Eva Illouz (2012) describes how the deregulation of partner choice has definite positive effects like free choice of a romantic or erotic lover, but also structural downsides which produce romantic suffering. With the term deregulation, Illouz refers to the detachment of romantic and erotic encounters from committed relationships. This means that having a romantic or sexual encounter with someone does not require or entail a long-term romantic partnership. In contrast, in premodern regulated partner choice until the $20^{\text {th }}$ century, romantic feelings and erotic encounters resulted from a committed relationship. Without wanting to depart from modern values like liberty or autonomy, Illouz argues that the deregulation of partner choice has facilitated a historically new power of men over women which is the power to dominate women emotionally through their willingness to commit to a relationship. Thus, the deregulation of partner choice seems to be both a triumph and a burden of love (Illouz, 2011, pp. $30,254)$.

However, Illouz's argumentation targets especially women who want a heterosexual, monogamous relationship with the prospect of a biological family. From a perspective of social agents, who want to depart from traditional relationship worldviews and who try to find their own way of loving and having sexual encounters in non-monogamous and non-heteronormative settings in which a long-term partnership does not necessarily need to consist of a wife, a husband and biological children, Illouz's observances might sound like an old-school problem. Do non-heteronormative and non-monogamous lovers remain unaffected by the downsides of deregulated partner choice?

Leaving a traditional relationship worldview behind goes hand in hand with reconsidering the appropriate conditions for sexual encounters and vice versa (Barker, 2018;

\footnotetext{
${ }^{1}$ Acknowledgements: I would like to thank my friends in heart and in conversation for helping me to keep an active interest in my intellectual and in my communal activities. For critical text feedback and discussions, I am especially grateful to Beate Absalon, Felix Ruckert, Jana Scherle and Tobias Wieland. I am greatly obliged to the helpers of the Journal for Positive Sexuality and their productive support.
} 
Easton \& Hardy, 1997; Ryan \& Jethá, 2011; Schott, 2020; Veaux \& Rickert, 2014). In a world in which romantic and erotic encounters take place only within a committed relationship, the question of how romantic feelings and sexual encounters correlate does not need to be answered. On the contrary, in a world of deregulated partner choice, different social forms of romantic and erotic bonding reflect different answers to the question how love and sex hang together. Once questioning heteronormative monogamous culture, it appears that sexuality has more facets than biological sex (male or female), sexual orientation (heterosexual or homosexual) and a particular type of sexual practice (penetrative genital stimulation) within a particular social narrative (lifelong marriage and family).

Having said this, sex-positive spaces seem to host people who are curious about exploring different facets of sexuality, for instance sexual attraction, preferences and desire; emotional attraction and expression; or sexual expression and practices as well as biological sex, gender identity and gender expression. Moreover, people who visit certain sex-positive spaces seem to be curious about finding ways to form relationships according to their individual needs rather than unreflectingly pursuing heteronormative, monogamous partnerships with a fixed outcome. Nevertheless, it is important to notice that departing from a heteronormative monogamous culture neither cancels heterosexuality and monogamy nor does it say that participants in sexpositive spaces are not heterosexual and/or monogamous. Presenting the downsides of heteronormative monogamous culture does not attack heterosexuality or monogamy, but it illustrates the negative effects of framing romance and sex within a rigid worldview of only two sexes and it considers the prospect of different possible types of loving relationships which can coexist with each other.

In this text I treat sex-positive spaces as a cultural environment, in which two transformative dynamics come together and represent the detachment of romantic feelings and sexual encounters from committed relationships. These are the readiness to reconsider different types of romantic relationships and the readiness to explore sexual encounters and sexuality outside committed relationships. In brief, I treat sex-positive spaces as an environment in which people explore different ways of relating to each other (Heckert, 2010). Thus, these spaces are experimental areas for deregulated partner choice. On the one hand, I want to motivate a reflection about the emancipatory potential of sex-positive spaces. On the other hand, I want to consider how far they risk fostering socio-political domination because of their experimental character. For this endeavour, it will be necessary to take a closer look at Illouz's analysis of deregulated partner choice and its effects on romantic suffering in the first section of this text. In the second section, I offer a systematic description of sex-positive spaces. In the concluding part, I will present possible traps of sex-positive spaces when it comes to unintentionally reproducing social conditions even though they might be aspired to be overcome.

I hope my reflections will contribute respectful insights about the correlation between heterosexual monogamy and romantic suffering, informative descriptions about sex-positive spaces as well as productive comments for navigating in such spaces. Eventually, I hope that I can make visible, in how far the perspectives, skills and insights which underlie characteristics of sex-positive spaces show that sex-positivity is not sufficiently described by referring to valuing, promoting or having (more) sex. Sex-positivity is an attitude that addresses the question of how people want to live with each other, how they can connect and stay connected and how they can 
enjoy themselves individually as well as in each other's company. In this sense, integrated sexpositivity addresses fundamental communal principles of living in a society. Thus, it is a profound answer to the question how collective co-happiness is possible.

\section{Emotional Suffering and Gender Inequality in Romantic Relationships}

In Why Love Hurts, Eva Illouz (2012) argues that a historically new power has developed in contemporary romantic, monogamous, heterosexual relationships which - among other factors - fuels emotional suffering in such relationships. Illouz demonstrates how a liberation of free romantic choice and erotic possibilities has developed into a structure that produces systematic gender inequalities and helps to maintain a power imbalance of men over women in romantic relationships. Illouz develops her argumentation describing the contrast between regulated middle-class partner choice in premodern times until roughly the middle of the $19^{\text {th }}$ century and partner choice in modern times since the beginning of the $20^{\text {th }}$ century. For her analysis of the differences between courtship in premodern and modern times, Illouz uses the novels of Jane Austen for the first. For the latter she uses qualitative interviews. In the beginning of this section, I will first present the characteristics of (de-)regulated partner choice, so that I can subsequently explain Illouz's thesis of an emotional power imbalance and the role that romantic love has for the genesis of self-worth.

In order to understand Illouz's sociological approach, it is helpful to notice that she does not locate the causes of modern romantic suffering in psychological pathologies but in the social and political structures in which people try to live and love each other. According to Illouz (2012), pathologizing dismisses the option of understanding the societal conditions producing systematic patterns of action. Thus, instead of problematizing deficient individual action, Illouz asks which societal conditions facilitate, motivate and legitimize certain patterns of action (pp. 137-139).

\section{(De-) regulation of Partner Choice}

In a $19^{\text {th }}$ century middle-class biography, a long-term relationship in the form of a marriage was scheduled both for men and for women and framed by social class affiliation. Partner choice across different social classes or ethnicities was not common. Personal questions like whether a committed relationship is wanted, what form it should have and who could be the right fit were not up for debate. Structures of emotional commitment evolved because all sexes were dependent upon marriage in order to gain status and survive socially and economically (Illouz, 2012, p. 125). Marriage had an overt economic character and was embedded in family structures, since it encompassed the transfer of family property to the husband, the dowry. The dowry could be reclaimed in the case of separation or divorce in order to prevent male capriciousness (Illouz, 2012, p. 69). It had the functions to strengthen the husband's bond and to anchor the relationship in a system of domestic, economic and societal obligations (Illouz, 2012, p.127). The family monitored courtship and examined the potential husband, which clearly limited a woman's liberty but also gave her security in the case of betrayal (Illouz, 2012, pp. 5558).

Because male agents had to prove their true intention of wanting to marry, the excessive exhibition of their affection affirmed social norms and was not interpreted as neediness. Rather 
than putting men at risk, the exhibition of intense feelings assured the family of the man's honorable intentions. During courtship, women were more reactive and thus emotionally less exposed than men. Female reservation in expressing emotions and sexual desire was a Christian norm, identifying virtue with female abstinence and self-control. It was the price women had to pay for moral equality and social recognition (Illouz, 2012, pp. 121-123).

In the $19^{\text {th }}$ century, courtship followed a normative choreography of rule-guided rituals, which mediated the emotional entanglement. Public knowledge of this choreography caused semiotic consistency. Rituals and rules supported agents to enter and exit relationships and it helped to prevent uncertainty in courtship (Illouz, 2012, p. 59-76). The promise, which expressed commitment, was central. Its function was to end courtship and stabilize the bond (Illouz, 2012, p. 73). Both the rigid interdiction of breaking a promise as well as the rule that intentions, utterances and actions needed to be consistent, served to make deception less probable and bring about certainty in the interpretation of courtship behaviour. Reputation, as the ability to keep one's promises, was a major requirement both for men and women; breaking a promise was socially sanctioned (Illouz, 2012, pp. 64-66, 70-73).

Illouz (2012) calls the system in which courtship was pre-structured and in which feelings were brought about by rituals and expressed only after the partners had passed the chronology of appeal and commitment, a regime of performativity of emotions (p. 62). In this regime, rules organised emotional experiences and their expression. Illouz (2012) calls the modern replacement a regime of emotional authenticity in which emotions do not follow from commitment but pre-exist commitment and encourage it. In the regime of emotional authenticity, individuals gain insight about their feelings through introspection or an overwhelming revelation such as love at first sight (p. 64). According to Illouz (2012), modern intimacy demands that a relationship originates in authentic feelings shared by both partners. In order to gain recognition and to fuse the identities into a loving $W e$, the lovers reveal their true self to one another while they also have to maintain their autonomy (p. 77). However, the bonding based on authentic feelings is impacted by the necessary reproduction of the reasons out of which the relationship was favored. This is so, because feelings can change in the near future and because choices are not finite in modernity (Illouz, 2012, p. 78).

In opposition to modern times, the evaluation of a person's character was a public act in the $19^{\text {th }}$ century. People had to act out an inner life that expressed publicly-shared values (Illouz, 2012, p. 82). The correspondence of character and societal norms served as a source for public recognition and it coined reputation. While the individualization of decision-making based on personal taste did liberate the individual will from normative confinements, it also weakened a source for social recognition (Illouz, 2012, pp. 79-81). Emotional intimacy, psychological compatibility and erotic charisma became new criteria in partner choice (Illouz, 2012, p. 82). But the transition from objective partner choice criteria (wealth, class, education) to subjective criteria (personality, attractiveness) made emotional rejection harder to bear. In modern times the reason for a romantic rejection is no longer an objective lack of wealth, but the person with her insufficient qualities, which she needs to exhibit nevertheless in order to reveal her true self (Illouz, 2012, pp. 68-69). Hence, what is at stake in modern courtship is the individual character of a person. 
Summarized, a world of deregulated partner choice is a world in which there is no more obligation to engage in a life-long romantic relationship. If a permanent romantic relationship is appealing, then there is no obligatory single form, such as a heterosexual marriage, to which this relationship has to conform. Partner choice is no longer necessarily endogamous, which means that partnership across different social classes, ethnicities and educational backgrounds is possible. There is no more default choreography of chronological rule- and code-following within courtship. In a world of deregulated partner choice, romantic relationships result from free choice and authentic feelings. Instead of the family, the individual chooses a romantic partner and she is also the carrier of choice-relevant qualities. Eventually, the self of a person is no longer defined by family or class affiliation but understood as an autonomous entity unmasking its authentic character in a romantic relationship.

This concluding description might appear to be more or less the case in at least some $21^{\text {st }}$ century Western societies and it is probably more appealing to modern readers than regulated partner choice, since the limitations of the latter seem to be so obvious; agents are excessively restricted in their individual scope of action, they are continuously observed and monitored, and they are not appreciated for their intrinsic value. Instead, they gain value through criteria such as wealth and status. Hence, the departure from a normative framework of courtship seems to be a triumph of free choice and romantic love. However, in the next part of this section I will explain Illouz's thesis that the departure from social regulation has facilitated the development of selfregulated marriage markets where the internalized economic character of intimate relationships is concealed and privileges are unequally distributed among male and female agents without people's awareness. But instead of tackling the social structures that produce inequality and further romantic suffering, suffering is interpreted as a consequence of a problematic female psyche so that self-doubt has become a female concept; women in particular are charged with psychological hygiene and the cure of character, thus redirecting resources which would be necessary in order to bring about societal change.

\section{New Emotional Power of Male over Female Agents}

The detachment of romantic and erotic encounters from regulated moral guidelines facilitated the development of self-regulated marriage markets, which Illouz (2012) also calls the sexual field (pp. 100-101). On marriage markets, individuals have more or less demanded qualities and hence they have more or less success in mating. Because partner choice is individualised, there is an open competition of individual agents, which effected a change of adequate trade objects. In Jane Austen's novels male and female agents exchanged equal goods (class, wealth, educational level). By contrast, in modern times individuals may exchange asymmetric attributes like economic status and sexiness (Illouz, 2012, pp. 101-102). In short, on the sexual field, competition is free for anyone (no endogamous exclusion), the criteria for decision making are individualized, so that asymmetric attributes can be exchanged, agents have internalized economic principles and individual choice is based on qualities expressing the authentic self of a potential partner, which is why success on the sexual field affirms a person's value (Illouz, 2012, p. 103).

Illouz (2012) argues that an important change in modern sexual relations consist in the entanglement of sexual desire and economic value (p. 113). She explains in how far culture 
industry has installed an understanding of both femininity and masculinity according to sexual attractiveness, which is why sexiness has become an important factor in partner choice, individual self-design and eventually an important factor in developing social status (Illouz, 2012, p. 89). However, male agents have experienced a decrease in power in the three domains of the working space through bureaucratization, the domestic household through feminist movements and in areas reserved solely for men through the heterosexual design of leisure facilities. As a result, sexual success has become the new male status symbol (Illouz, 2012, pp. 140-141.) in a social environment, in which sexual liberty is promoted and an industry of film and photography as well as cosmetic-, fashion- and advertisement-industries distribute an imagery of sexual attractiveness (Illouz, 2012, p. 86).

The amount of accumulated sexual successes is the simplest form of erotic capital (Illouz, 2012, p. 108). To be sure, it is true that erotic capital has also become economic capital for women, in so far as they may trade attractiveness for wealth in order to gain social status. However, Illouz argues that male and female agents channel sexuality differently, since they have different strategies to gain social status. While erotic capital directly furthers male social status, it only contributes to female upward mobility if women manage to manoeuvre their erotic capital towards a committed relationship. This is why female sexuality remains subordinated under biological reproduction and marriage, whereas for men sexuality has become the most important arena for exhibiting their status. Because of the detachment of erotic and romantic encounters from committed relationships, male and female sexual strategies separate into serial sexuality on the one hand and emotional and sexual exclusivity on the other. Since sexual seriality goes along with emotional distance, it supports male agents in dominating the sexual field. However, for women serial sexuality has always existed in parallel to sexual exclusivity since the former seems to be the strategy for securing the latter (Illouz, 2012, pp. 195-199).

In addition, men still control the greater part of economic property and cash flow, which is why committed relationships are still of decisive importance for women (Illouz, 2012, pp. 107108). Partnership with a male agent still is a major factor in securing the societal and economic existence of women. This is a systematically produced motivation for women to invest in committed relationships (Illouz, 2012, p. 151). But since relationships have become optional, this brings about advantages for male agents and their liberty of choice. While women frequently depend on partnership in order to secure their economic survival, men do not suffer from the same economic pressure and may enter and exit relationships without bearing the same economic consequences, which impacts people's readiness to make compromises and what they are willing to bear in relationships.

Based on the assumptions of the detachment of erotic and romantic encounters from committed relationships as well as the unequal economic necessity that committed relationships have for male and for female agents, Illouz (2012) argues that men have developed a new form of control over women on the sexual field (p. 108). Men gain and maintain their power over women and over other men through the accumulation of sexual successes. In the social context of a marriage market, male power translates into access to a greater amount of sexually available women, which is how sexual success has become the socio-economic status symbol for men (Illouz, 2012, p. 141). Because men, unlike women, are not only not sanctioned for accumulative sexual strategies but are also rewarded for them, and because male agents no longer profit from 
marriage and a traditional family in terms of their social status, a social structure has developed which rewards men for not committing to romantic long-term relationships with one female agent, but instead for accumulating sexual successes. This social structure allows men to emotionally control women through their readiness to commit to a relationship (Illouz, 2012, p. 166).

A final factor that furthers men's power over women in romantic relationships, is the effect which deregulated endogamous partner choice has on competition between women on the sexual field. Because of the modern possibility of bonding across different classes, ethnicities and educational backgrounds, a greater amount of selection options became available. Again, this seems to be more problematic for female than for male agents since women have less time to form committed relationships which might lead to a biological family, and they have fewer selection options than men (Illouz, 2012, pp. 147-150). This is due to the following reasons: for the sake of education or work, women prolong their decision for a family; at the same time female fertility is biologically more restricted than male fertility. Moreover, the information of restricted female fertility is widely distributed through new information technologies, so that female courtship behaviour is interpreted as neediness in the context of the assumed female desire to form a family. In addition, statistics indicate that women tend to choose men of their age or above their age and they seem to choose men of their educational level or above their educational level as romantic partners (Illouz, 2012, p. 152). However, in accordance with feminist achievements, the number of educated women steadily increases whereas the number of educated men has increased to a much lesser degree since 1980. Statistics also indicate that men neither restrict their partner choice to a specific female age group nor to a female group of particular education (Illouz, 2012, p. 152). As a result, statistically, male agents have more mating options than female agents.

In a nutshell, because there is no dictate to marry, no external incentive like dowry, unequal economic necessity to form a committed relationship between men and women, no more mandatory connection between romantic and erotic encounters, child birth and committed relationships, unequal time restriction concerning fertility and unequal amounts of selection options for male and female agents, men are privileged to live out their autonomous life more consequently and for a longer period of time, which gives them power to dominate women emotionally (Illouz, 2012, p. 254).

\section{The Role of Romantic Success for Self-Worth}

In premodern times, class affiliation and regulated courtship dictated the behavior, which, if performed satisfactorily, would bring about social recognition. Because of the removal of class affiliation in modernity, the genesis of individual worth shifts to personal and especially to romantic relationships (Illouz, 2012, p. 214). Why can people not generate self-worth on their own and why are romantic relationships assumed to be so important in order to generate selfworth? For the social philosopher Axel Honneth, the recognition of a person in a romantic relationship promises social existence. The fear of being emotionally rejected really is a fear of being invisible, that is, being socially worthless (Honneth, 2003, pp. 10-27). Thus, the fear of emotional rejection indicates the importance of a romantic relationship for social value and its impact on self-worth (Illouz, 2012, p. 230). 
Furthermore, I assume that the central role of romantic love in generating self-worth also derives from love's characteristic to bestow value on someone, which is often expressed by articulating affectionate emotions towards the beloved. This however only serves to explain love's function in contributing to self-worth, but it does not explain why romantic relationships are assumed to be the main source for self-worth. Illouz (2012) argues that, especially for women who gain less recognition through public channels, recognition and validation are important incentives to commit to a romantic relationship (p. 247). This is why women need romantic relationships to fulfil the function of generating self-worth. Men do not seem to be dependent upon female recognition in the same way, since according to Illouz, both men and women are in need of male recognition and approval in order to establish self-worth (Illouz, 2012, p. 279).

Serving as the central stage for establishing self-worth is only one demand that stresses romantic relationships. It is another challenge to relieve tension between the need for recognition on the one hand and the importance of autonomy on the other. I have suggested that self-worth has an inherent social character and develops through recognition practices. Recognition practices have shifted towards romantic relationships where they have the form of expressing loving emotions for one another. However, the practice of expressing affection towards a beloved is troubled by modernity's imperative to exhibit autonomy. As a result, individual emotional expression is being monitored in order to maintain a position of strength. Thus, recognition and autonomy are in conflict (Illouz, 2012, pp. 242-243).

Furthermore, the aim to secure autonomy causes both a commitment inhibition and an inhibition to ask for commitment. Because autonomy has such importance in modernity, the pledge for commitment has become illegitimate. Romantic partners are expected to exhibit their own autonomy but also preserve the other person's autonomy, which is translated into not demanding anything. In this structure, a promise is understood as limiting the freedom of another person to feel differently tomorrow. At the same time, though, romantic relationships have to serve as a source for recognition (Illouz, 2012, p. 248). Many of Illouz's female interviewees report their inhibition to ask for commitment in order to avoid the impression of neediness or the secret plan to drive a man into the family trap. However, Illouz (2012) argues that experiencing the question for commitment as problematic only makes sense if autonomy has already ruled out recognition (p. 245).

So far, I have explained the role of recognition in the genesis of self-worth, that this phenomenon is a modern phenomenon because individual worth has become detached from social class, why romantic relationships have become the stage for negotiating self-worth and how the constitution of self-worth is being complicated by the lived consequences of the importance of autonomy as a modern value. In this theoretical framework, Illouz (2012) claims that men are privileged to follow autonomy's imperative more determinedly and for a longer period of their life, which is why they can emotionally dominate the desire of women, who want a committed romantic relationship (p. 254). Thus, male agents control the rules of commitment as well as the rules of recognition (p. 251), which has been facilitated through the detachment of sexual and romantic encounters from committed relationships (Illouz, 2012, p. 143).

According to Illouz (2012), therapy culture does not name the societal structures and reward mechanisms, the reflection of which could further an awareness of the systemic problems 
so far described. Instead, it encourages lovers to investigate their individual problems, which they bring to their relationships and which they need to cure in order to be able to have a satisfying romantic relationship. Illouz argues that women especially are being encouraged to first start loving themselves, which makes women feel deficient if they love the way that they are being taught to love, which is the exertion of care (Illouz, 2012, p. 273). As a result, women accuse and doubt themselves as a response to romantic problems. The focus on individual deficits conceals that female self-accusation is a result of an unequal distribution of the privilege of autonomy between men and women. As a consequence, self-doubt becomes a female figure of thought. This indicates that women especially find themselves torn between autonomy and recognition while they lack the social anchoring that would be necessary in order to generate self-worth and escape the damaging mechanism of contemporary romantic culture (Illouz, 2012, p. 277).

\section{Deregulated Sex-Positive Spaces}

The reason why I care to comprehensively communicate Illouz's analysis of romantic suffering is that I believe that some of the promising attributes in a contemporary sex-positive culture can be lost if the previously discussed socio-cultural context and the respective power dynamics remain invisible and people uncritically follow the idea that "everything is always possible." Since Illouz argues that the deregulation of partner choice consists in the detachment of erotic and romantic encounters from committed relationships, I look at corresponding unregulated phenomena here. What I call deregulated sex-positive spaces are semi-public communal meeting spaces allowing sexual interaction. I developed the following contents via critical discussions with a variety of people who understand themselves as being interested in sex-positive culture in one way or the other - some of them for thirty years or more. Amongst them are practitioners, artists, academics, therapists, body workers, sex workers, mediators, activists, educators, writers and students. If Illouz is correct, then under certain circumstances deregulated sex-positive spaces may offer an optimal stage for men to accumulate erotic capital, gain social status and extend their privileges, while women devote themselves to self-love and follow serial sexuality in order to arrive at sexual exclusivity and secure their social existence.

\section{Regulated Sex-Positive Spaces}

Not all sex-positive spaces are deregulated spaces. Brothels or swingers' clubs for instance usually have policies that share certain criteria and that regulate how sexual contact is being conducted. Contrary to deregulated sex-positive spaces, these spaces typically reproduce heterosexual couple constellations, and they have the function to facilitate sex. People go to swinger parties and to brothels in order to have sex. Similarly, the expectation to have sex might also take place in the private bedroom. In this context it is likely that the understanding of what sex $i s$ is guided by a narrow idea of a traditional sex-script that starts with foreplay, has penetrative genital stimulation at its center and aims at orgasm (Kalman, 2016). In contrast, a wider understanding of "having sex" might build upon a person's capability to be aware of her own body history, to enjoy sensual pleasures of the whole body and to enjoy the intimate company of others. Private bedrooms, brothels and swingers' clubs are examples for what I want to label regulated sex-positive spaces, which frequently but not exclusively have (heterosexual) 
couples as their focus and which take place in a normative framework within which either party acts according to the expectation to have penetrative sex

\section{A Non-Heteronormative Communal Space without a Sex-Script}

The sex-positive spaces that are part of a cultural movement which seeks to work on the social attitude towards body awareness, bodily pleasures, sex and sexuality, differ from these regulated spaces. In this article I refer to them as deregulated sex-positive spaces. However, that does not mean that there are no rules, codes or principles. Especially the principle of consent is central in such spaces. Deregulated sex-positive spaces try to depart from heteronormativity, from a narrow sex definition and from the expectation to have sex. They give permission and opportunity to investigate practices of relating to one another in a bodily, sensual and sexual way. The difference between entering a space in order to have sex and entering a space in which sexual encounters are invited might not appear to be big. However, it does make a difference whether people focus on sex as their aim, or whether they do not have to leave a space if they want to engage with each other sexually. The attempted avoidance of a specific sexual aspiration offers space and time (Ruckert, 2018). Without the concrete intention to, let us say, penetrate someone, people get together as a group and find out what is possible in this specific social scenario. They create and pick up a dynamic that comes into being by a collective's interactions. The experience of having space and having time to expand and to find an intuition enables different participation, and it encourages different expectations and motivations to improvise, to create and to co-create a space. This is a collective and an aesthetic potential of sex-positive spaces.

\section{A Risky Space of Self-and Collective Responsibility}

Sex-positive spaces that invite sex but do not regulate what is going to happen, are risky and complicated for at least two reasons: people certainly do have desires and wishes, and they seek satisfaction. Being in a space that offers the possibility of this satisfaction might drive a person to forcefulness. Sometimes a desire might be so urgent that a person rushes forward, gets rejected, withdraws, tries again, and therewith creates an unstable position that causes insecurity. Another reason why sex-positive spaces are risky is that probably most people's sexual biography integrates negative, shameful or even traumatic experiences. It is common to psychologize about the psychic situation of people whose sexuality diverges from normative standards. But just like non-normative sexual desires have their respective learning history, all other desires also have a learning history. And since we still live in a sex-negative culture that associates matters of sexualities with fear and "perceived threats of actual or potential pain" (Williams et. al., 2015, p. 10); that offers a vast number of dominant negative narrative models (abuse, coercion, affairs, STDs, unwanted pregnancy); that communicates homogenous body norms and uniform sexual practices; and that furthers taboo, shame and interdictions, I find it most likely that every person carries her baggage. This baggage might become problematic in a sex-positive space, which could cause a vulnerable and existential situation. 


\section{An Emotion-Positive Space}

Deregulated sex-positive spaces not only invite sexual encounters in their variety but also emotions in their variety. They tend to be kind(er) with emotions that have a negative connotation - at least accepting and welcoming them like the happy and positive facets that people also have. A possible attempt behind this is to avoid cherry picking of socially wanted features - pleasing features that do not rub society the wrong way. Instead, a big or a very thin body, an old body, burned, torn or loose skin, a limp penis, sexual un-arousal, crying and crashing, failing and the vigorous outburst of repressed emotions are invited. The presence of this variety might invite participants to appreciate and value different body forms, diversity of sexual practices and holistic emotional landscapes. But eventually, I would argue, it is not the aim to positivize what had been framed negatively but to relieve sexuality from value judgement (Emcke, 2013).

\section{A Semi-Public Space Enabling Visibility}

Since deregulated sex-positive spaces are collective situations, they oscillate between private and public. On the one hand, they are sheltered in a way that they take place in a room and within a designed scenario or a frame. On the other hand, they are public and they expose participants. For many, voyeurism is participation (as the character Justin Bond postulates in the movie Shortbus, 2006), so that an observant position is just another position in the collective situation. Moreover, the public character facilitates an awareness of variety. A variety of gender identities, gender expressions, desires, sexual practices and body forms is invited to become visible.

Since visibility can also have negative effects, such as presenting dominant role models that determine and limit meaning, enabling institutional control, or suggesting forced confession (Foucault, 1978), it seems that visibility does not have intrinsic but instrumental value. In a socio-political dimension, visibility might be the condition for an awareness of variety or for democratic participation. Concerning deregulated sex-positive spaces it might be observed that visibility is a condition for connection. The relation between visibility - what is to be perceived, how is it perceived, and the interpretation of the perceived on the one hand and a plenitude of ways that people can connect with each other on the other hand, is put on stage and played with. Practices of looking, gazing, observing, flirting, sensing or inviting become modulations of connection based on the principle of visibility.

\section{Learning Culture}

The aspect of visible diversity offers a multitude of models and it contributes to a learning culture. Therefore, a common feature of deregulated sex-positive spaces is a (selforganized) workshop structure in which people who have an expertise in a certain field, invite others to practice. Because of the present variety in a deregulated sex-positive space, people tend to have a broader view on what sex is. Arousing talk, caressing participation in a group scenario, watching or masturbating might all be perceived of as having sex or being sexually engaged with others. Diversity facilitates possibilities. Since some activities might not be inviting to everyone 
in the same way, practices of negotiation and clarifying the meaning of a fantasy are important features of deregulated sex-positive spaces.

\section{A Space of Negotiation and Consent}

Negotiation takes the place of psychologizing and normative judgement. The aim of negotiation is to achieve consent. In a political setting, consent differs from a majority vote in that it is a procedure which strives for acknowledging each person's needs, wants and emotional situations - and which takes them into account for decision making. The concept of consent has a major standing in a deregulated sex-positive setting since there is the attempt to avoid emotional and bodily border crossings. In the BDSM scene, consent serves as the criterion that distinguishes voluntary sexual practices from violence. In order to juristically distinguish BDSM from abuse and in order to achieve a self-understanding that does justice to the caring aspects of BDSM practices, the BDSM scene emphasized their liberal decision to do exactly what they want to do. This coined the concept of liberal consent, which says: I know what I am doing and I want to do it (Bauer, 2016). Over time, the character of this liberty has been challenged, since sexual actions develop and might turn into something which couldn't have been conceived of in the beginning of the encounter. Moreover, wanting can be the object of external influence and pressure as well as internal epistemic unawareness. Thus, the concept of critical consent has developed, which emphasizes its character of a work in progress and its need for (communicative) updates while the interaction takes place (Bauer, 2016, pp. 135-139). What is encouraged in this process of gaining more certainty about what an individual wants and what someone else wants is staying in communicative non-violent contact, gentleness and error friendliness.

\section{A Play Space}

Eventually, spontaneous collective movement, the visible presence of sexual diversity and inspiring models within an affirmative and clear consensual framework, motivate people's drive to dare, to explore, to improvise and to play. Deregulated sex-positive spaces are play spaces. A playful attitude incorporates humor, aimless attempts, giving something a try, failing, making mistakes, and being kind with mistakes (Kalman, 2016). A distinctive feature of playfulness is that people generally tend to be rather happy. Deregulated sex-positive spaces tend to be spaces of laughter, play, togetherness, de-stressing and wellbeing.

\section{Possible Traps of Deregulated Sex-Positive Spaces}

If Illouz's analysis is sound, then agents who meet in monogamous, heterosexual erotic or romantic encounters differ in their conditions regarding the socio-economic necessity of a committed relationship, the necessity of a committed relationship for the genesis of self-worth, the available time to form a committed relationship with a prospect of a biological family, the social interpretation of their bonding behavior, the competition on the sexual field, the status that derives from sexual success, the resoluteness in which they can live their autonomy, the available time for living autonomously before parenting, the psychological interpretation of their suffering and insecurities and the learning history of appropriate romantic expressions. If only a third of this is true, then the heterosexual, monogamous romantic situation is miserable from an 
emancipatory point of view and there is an urgent need to rethink romantic and sexual culture. How can sex-positive spaces manage these challenges? The rest of this section will have the form of questions rather than finite answers.

Erotic capital. Sex-positive spaces may fall into the trap of concealing the difference in status which men and women take away from their sexual successes and failures. If men acquire social status through the accumulation of sexual success, then certain individuals will have more status in sex-positive spaces than others, which allows them an easier sexual access to a greater number of women. However, while erotic capital directly increases male social status, Illouz (2012) argues that sexual successes further female social status only indirectly - if women manage to turn their erotic capital into a committed relationship. This frames the participation of men and women in sex-positive spaces differently. In the worst-case scenario, sex-positive spaces offer a stage to foster male erotic capital, while women exercise sexual liberty instrumentally in order to encounter someone with whom a committed relationship is possible. Moreover, Illouz (2012) argues that there are fewer selection options for women than for men on the sexual field. It is possible that this number further decreases since sex-positive communities are still rather small communities. And since sex-positivity is an attitude towards social life with an existential set of values, it is likely that participants of sex-positive spaces may want to form a relationship with a person who shares this set of values.

Sex and money. Illouz (2012) maintains that modern sexuality is characterized by the entanglement of economic principles and desire. What she has in mind is, for instance, the idea of weighing the best choice or calculating the most promising investment (of attention) for the best possible outcome. I hold it to be possible that the sustainability of sex-positive culture also depends on the extent to which communities find alternative ways to deal with financial resources. It is important to notice that some sex-positive events last between three and ten days and that the participation can cost a considerable amount of money. Moreover, individuals need to be able to afford not going to work within the respective time frame. Sometimes, participation is cheaper if participants work at the event. However, some events structurally depend on people who need to work as a helper if they want to participate in the event, which could lead to exploitation of socially disadvantaged people. In addition, certain style standards, gear for sexual practices or practices of body maintenance require financial efforts to buy clothing, gear and health food, to go to yoga classes and fitness facilities, to purchase beauty products or to go to a hairdresser. This might appear not to be different from a night spent in a cocktail bar and a dance club, which are possible dating environments where people stage their attractiveness. However, a critical perspective on the entanglement of capitalist economy and attractiveness needs to consider alternative ways to facilitate access to sex culture, as for instance through funding models such as pay as you like (PAL).

Equality Illusions. Sex-positive spaces may fall into the trap of enforcing and concealing power imbalances between the sexes, especially since visitors to such spaces might think of themselves as emancipated, open-minded and sharing values of equality. However, agreeing with the values of equality and emancipation in discourse does not guarantee the ability to habitually implement them in public life and in relationships. In fact, Koppetsch \& Burkhart (1999) and Koppetsch \& Speck (2015) suggests that couples might think that they have an equal relationship because they agree with the value of equality. However, in practice they do not equally distribute responsibilities and chores, leisure privileges and the opportunity of self-realization. This 
discrepancy withholds privileges from women and it also withholds power and recognition resulting from the accomplished work if the partners pretend that they equally distribute opportunities and duties. However, pretending to have an equal relationship nurtures the selfimage of modern partners with emancipatory values and it secures domestic harmony - two goods that will not be given up easily. This might be why Andie Nordgren (2012), the author of The short instructional manifesto of relationship anarchy, assumes that people who want to bring about change need to talk about what they are doing (differently); otherwise they end up reproducing the norm.

Pseudo-therapy. As environments dealing with the body, emotions and sexuality, sexpositive spaces can easily get confronted with the sometimes violent effects produced by a sexnegative culture. As a result, sex-positive spaces are not only learning spaces, political spaces or aesthetic spaces but also frequently understood as healing spaces. Thus, concerning the emancipatory interests of a sex-positive culture, they may fall into the trap of reinforcing therapeutic tendencies, encourage a focus on individual problems of the psyche, distract from systematic inequalities and occupy the personal and social resources which are necessary for socio-political change. Moreover, if it is true that women are already prone to self-doubt and self-accusation (Illouz, 2012), they could fall into the trap of submitting to moral superiority, advocating generosity and compersion while silencing their anger and inner revolt, which could help to take actions against conditions that are not equally good for all participants. In addition, deregulated sex-positive spaces are not professional clinical or medical therapy environments. However, body practices, work on emotional expression or verbal exchange about sexual content may encourage psychologizing a personal biography without having the respective professional skills in order to mediate such a process if an emotional damage is being touched upon.

Talk intimacy and confession culture. The emphasis on expressivity, authenticity and communication in deregulated sex-positive spaces might create the illusion that intimacy generates from stripping naked in conversation. Esther Perel calls the idea of creating intimacy through excessive verbal exchange talk intimacy (Perel, 2007, pp. 44-46). There are several traps to this: most obviously, talk might not be everybody's channel to generate intimacy. Moreover, stripping naked in conversation does not necessarily lead to intimacy but could lead to nondistance, which might put people in an inappropriate proximity with each other (Han, 2015, p. 20). Another trap is pointed out by Foucault's indication that talking about individual sexuality might take the shape of a confession culture which facilitates institutional regulation (Foucault, 1978). The invitation to express desires and emotional states might occur as an opportunity to break through a tabooed speech culture and start a transparent discourse. But it could also further a reveal culture, in which people incautiously share personal information in an exposing and disadvantageous way. For instance, sharing intimate information with a community might trap one into building a dependent reward structure and rescue narrative, in which people are socially rewarded if they expose their vulnerable self.

Vagueness and ambiguity. Sometimes, terms for phenomena are dismissed as labels that limit people or phenomena and put them into a category or a drawer. However, terms are the linguistic clothing for what philosophers call concepts, and concepts are the cognitive resources for thinking. While terms can be ambiguous or polysemic, concepts cannot. Concepts can be more or less appropriate and they need to be updated, but as a network of beliefs they facilitate 
reference to and understanding of phenomena in the world. The trap in not wanting to label a relationship or be precise in its description in order not to limit it, or interconnect it with normative expectations, is that people might not understand their connection or relationship. Therefore, they might not understand when they are in a harmful relationship, when they are systematically disadvantaged and they might not be able to criticize aspects with which they are uncomfortable. If this is true, then it is hard to see where trust and reliability could be coming from.

Commitment inhibition and emotional sensation seeking. If Illouz is correct and recognition has been ruled out by the importance of autonomy, and thus, the request for commitment or a promise has become illegitimate, then it is hard to see how far the request for commitment can be asked without causing stress and being understood as a demand or a thread. Deregulated sex-positive spaces cover a plenitude of bodily, emotional, sexual and social learning areas such as dealing with shame, anger and rejection, speaking about sexual fantasies, recognizing and drawing boundaries or practicing negotiation. In face of the tension between commitment and autonomy and because the amount and density of emotionally and sexually engaging experiences is so high in sex-positive spaces, individuals may be tempted to continuously strive for the next thrill (Illouz, 2004). Hence, I assume that it might be helpful to also include commitment as a topic and an area of practice.

Missing social embedding. There are still few models giving examples for departing from a heteronormative, monogamous romantic relationship. Having fewer people who might give good feedback and who support the attempt to relate to one another differently, as well as a lack of guidelines and models for how to struggle through conflicts, find suitable decision making processes or renovate relationship agreements, might trap people in (social) isolation. If relating differently in romantic and sexual relationships is central for the way in which a community is built, then sex-positive spaces might contribute to a very different culture. However, if emancipatory attempts aim at social change and not at a parallel society, then sex-positive culture needs to be accessible and provide ways to bridge gaps.

Facilitation is not empowerment. Sex-positive spaces demand a high level of communicative skills, reflective skills, emotion regulatory skills, proprioceptive awareness, error friendliness, integrity and the willingness to embark on improvisation, learning and intrapersonal as well as interpersonal diversity and unfamiliarity. The reward, as I see it, is relaxed loving and a relaxed sex life.

\section{Conclusion}

Based on Eva Illouz's sociological explanation of modern suffering in heterosexual, monogamous romantic relationships, I have considered possible traps which deregulated sexpositive spaces might walk into. Despite its promise of liberal loving, Illouz holds the deregulation of courtship, that is, the detachment of romantic and erotic encounters from committed relationships, to be one major factor contributing to a social situation in which the privilege of autonomy is unequally distributed between men and women. This enables men to dominate women emotionally. Since sex-positive spaces can be understood as one form of deregulating erotic encounters, I followed the question whether these spaces are especially prone 
to reproduce social inequalities as described by Illouz, or whether they are especially suitable to overcome inequalities and bring forth emancipatory change.

My response is the following: deregulated sex-positive spaces are a part of sex-positive culture and activism. As such, they address fundamental dimensions of social life. The prospect is a society that figures out answers to many important how-to questions concerning personal and social life: how to show and communicate affection, how to relate to yourself and to your body, how to relate to other people and their bodies, how to find an appropriate proximity, how to get into and out of contact, how to maintain connection, how to deal with desire, how to negotiate bodily and romantic interests, how to deal with a diversity of emotions within people and among people, how to deal with failure and error, how to communicate borders firmly, how to reject someone with respect and how to deal with rejection, how to solve conflicts as a community while respecting personal space and so forth - the list is long.

The crucial point, as I see it, is that sex-positive culture needs to be good in practice and not only in theory. This is why Illouz offers both a reminder of how circumstances that are not intentionally arranged can still fall into place and the explanation to the normative suggestion that sex-positive culture needs to be feminist. While practice does encompass critical discourse and content work, it is also necessary to translate its contents into action. There is no good in theory but [...]. Relating to one another is exactly what people do in practice no matter whether they are in professional, personal or sexual contact. A social program is only as good as it is in lived reality.

\section{References}

Barker, M. J. (2018). Rewriting the Rules. An Anti Self-Help Guide to Love, Sex and Relationships (2nd ed.). Routledge.

Bauer, R. (2016). Vom liberalen zum kritischen Konsens. In A. Borkenhagen, E. Brähler (Eds.), Wer liebt, der straft? (pp. 129-142). Psychosozial-Verlag.

Easton, D., Hardy, J. W. (1997). The Ethical Slut. A Practical Guide to Polyamory, Open Relationships \& Other Adventures (2nd ed.). Celestial Arts, 2009.

Emcke, C. (2016). Wie wir begehren (3rd ed.). Fischer.

Foucault, M. (1978). The History of Sexuality. Pantheon Books.

Han, B. (2015). Agonie des Eros (4th ed.). Matthes \& Seitz.

Heckert, J. (2010). Relating Differently. Sexualities. 13(4). 403-411. https://doi.org/10.1177/1363460710370651

Honneth, A. (2003). Unsichtbarkeit. Stationen einer Theorie der Intersubjektivität. Suhrkamp.
Illouz, E. (2004). Zur postmodernen Lage der Liebe. In P. Kemper, U. Sonnenschein (Eds.), Das Abenteuer Liebe. Bestandsaufnahme eines unordentlichen Gefühls (pp. 251-259). Suhrkamp.

Illouz, E. (2012). Warum Liebe weh tut. Suhrkamp.

Kalman, H. (2016). Some Notes on Faking. In S. L. Adams, Sarah, C. M. Davidson, C. R. Lundquist, (Eds.), New Philosophies of Sex and Love: Thinking through Desire (pp. 257277). Rowman \& Littlefield International.

Koppetsch, C., Burkart, G. (1999). Die Illusion der Emanzipation. Zur Wirksamkeit latenter Geschlechtsnormen im Milieuvergleich. UVK.

Koppetsch, C., Speck, S. (2015). Wenn der Mann kein Ernährer mehr ist. Geschlechterkonflikte in Krisenzeiten. Suhrkamp.

Nordgren, A. (July $6^{\text {th }}, 2012$ ). The Short Instructional Manifesto for Relationship Anarchy. Retrieved September 9, 2020, from https://theanarchistlibrary.org/library/andienordgren-the-short-instructional-manifestofor-relationship-anarchy 
Perel, E. (2007). Mating in Captivity. Harper.

Ruckert, F. (2018, January). The Living Room Tour. Creating Sex Positive Spaces [Lecture Performance].

http://felixruckert.de/2017/12/05/the-livingroom-tour/

Ryan, C. \& Jethá, C. (2011). Sex at Dawn. How we Mate, why we Stray, and what it Means for Modern Relationships. Harper Perennial.

Schott, O. (2020). Lob der offenen Beziehung. Über Liebe, Sex, Vernunft und Glück (9th ed.). Bertz + Fischer.
Veaux, F., Rickert, E. (2014). More Than Two: A Practical Guide to Ethical Polyamory. Thorntree Press.

Williams, D., Thomas, J. N., Prior, E. \& Walters, W. (2015). Introducing a Multidisciplinary Framework of Positive Sexuality. Journal of Positive Sexuality, 1(1), 6-11. https://doi.org/10.51681/1.112 